\title{
Assessment of rodenticide resistance, eradication units, and pathogen prevalence in black rat populations from a Mediterranean biodiversity hotspot (Pontine Archipelago)
}

\author{
Sara Fratini $(\mathbb{D} \cdot$ Chiara Natali $\cdot$ Stefania Zanet $\cdot$ Alessio Iannucci $(\mathbb{D} \cdot$ \\ Dario Capizzi $(\mathbb{D} \cdot$ Iacopo Sinibaldi $\cdot$ Paolo Sposimo $・$ Claudio Ciofi $(\mathbb{C}$
}

Received: 5 June 2019/Accepted: 18 December 2019/Published online: 2 January 2020

(C) Springer Nature Switzerland AG 2020

\begin{abstract}
Biological invasions are a growing threat to biodiversity. The black rat, one of the worst pest in the world, is responsible for extensive population decline of many autochthonous and endemic species, particularly in island ecosystems. A number of rat eradication campaigns have been conducted, however, such endeavors do not always result in a complete removal of the pest. This may be due to the occurrence of individuals resistant to common rodenticides and/or a re-invasion of
\end{abstract}

Sara Fratini and Chiara Natali have contributed equally to this work.

Electronic supplementary material The online version of this article (https://doi.org/10.1007/s10530-019-02189-1) contains supplementary material, which is available to authorized users.

S. Fratini $(\bowtie) \cdot$ C. Natali · A. Iannucci · C. Ciofi Department of Biology, University of Florence, Via Madonna del Piano 6, 50019 Sesto Fiorentino, FI, Italy e-mail: sara.fratini@unifi.it

\section{S. Zanet}

Department of Veterinary Sciences, University of Turin, Largo Braccini 2, 10095 Grugliasco, TO, Italy

\section{Capizzi · I. Sinibaldi}

Latium Region, Directorate Natural Capital, Parks and Protected Areas, Viale del Tintoretto 432, 00142 Rome, Italy

P. Sposimo

Nature and Environment Management Operators Srl (NEMO), Viale G. Mazzini 26, 50126 Florence, Italy the same environment from interconnected areas when appropriate eradication units are not defined before starting an eradication campaign. Our study is a multidisciplinary approach whereby genetic and epidemiological methods were used to provide background information for successful eradication of black rats. We investigated the occurrence of mutations in the VKORCI gene known to confer resistance to rodenticides and evaluated the spread of zoonoses across three islands of the Pontine Archipelago, an Italian hotspot of endemic Mediterranean biodiversity and a possible mainland source of invasion. As part of an eradication campaign, we also assessed patterns of genetic diversity at 10 microsatellite loci in order to identify eradication units. We recorded a strong population structure and revealed at least two distinct eradication units. Some degree of admixture was recorded on Ponza, the largest island and likely the main source of rats invading the other two islands. We did not record the occurrence of rats resistant to anticoagulants, but we revealed transmission of vector-borne pathogens in commensal habitats of the Archipelago.

Keywords Eradication campaign - Rattus rattus . Biological invasions $\cdot$ Microsatellites $\cdot$ Zoonoses . VKORC1

\section{Introduction}

Biological invasions are a pervasive global threat to biodiversity, human health and food security, have a 
detrimental effect on the ecology of autochthonous species and a significant impact on ecosystem services (Vié et al. 2009; Vilà et al. 2010). The occurrence of alien species in particular, is one of the most severe menace to amphibians, reptiles, birds and mammals.

Rats are among the most invasive and dangerous pest species. They affect agriculture and natural vegetation and represent a threat to endangered and protected fauna, particularly in insular ecosystems (Doherty et al. 2016; Stenseth et al. 2003; Towns et al. 2006). Despite island invasions by rats occur mainly by passive transportation through sea routes, strict regulations involving ship inspections and biosecurity measures for docking ships are mostly lacking in many countries.

Besides being a threat to biodiversity, rats are also a danger to public and animal health (Capizzi et al. 2018; Davis and Calvet 2005; Webster et al. 1995). To date, more than 24 pathogens can be directly or indirectly transmitted to man by rodents (Meerburg et al. 2009). Vector-borne diseases (VBD), such as leishmaniasis, anaplasmosis, babesiosis and Lyme borreliosis, use rodents as intermediate or reservoir hosts and are the most noxious along with Toxoplasma gondii, which infects humans through the ingestion of contaminated food and water (Daszak et al. 2000; Dubey 1998; Rosso et al. 2017). The impact of VBD and $T$. gondii on public health is accentuated in insular habitats where epidemiologic conditions and population dynamics facilitate biological cycles of pathogens and their vectors (Zanet et al. 2014a).

Over the last decades, several rat eradication campaigns have been conducted to protect biodiversity and limit diffusion of zoonoses, particularly on islands (Graham and Veitch 2002; Howald et al. 2007; Keitt et al. 2011; Kerbiriou et al. 2004; Pascal et al. 2005; Towns et al. 2001). However, such endeavors do not always result in a complete eradication of the pest (Savidge et al. 2012). In fact, several factors may be responsible for the failure of an eradication program. One of this is the high capability of rats to re-invade the same environment by swimming across islands if the appropriate conditions are restored (Courchamp et al. 2003; Russell et al. 2008). Another possible cause of an ineffective eradication campaign is the failure to eradicate all individuals of a population because of, for example, the occurrence of resistance to rat poisons (Abdelkrim et al. 2007). Since the 1950s, rodent pest control has been conducted using first- generation anticoagulant rodenticides, such as warfarin, diphacinone and chlorophacinone. These compounds proved to be very effective in controlling rodent populations as they inhibit blood clotting by blocking Vitamin K reductase reaction and kill rodents relatively quickly. However, their massive use has been responsible for the establishment of resistance to anticoagulants, observed for the first time in 1958 in England (Boyle 1960). Anticoagulant resistance also leads to direct and indirect environmental damages. Rodents may continue to spread zoonotic diseases such as hantaviruses, echinococcosis or leptospirosis (e.g. Meerburg et al. 2009) and consume large amount of toxic baits, thus exposing their predators to secondary poisoning via bioaccumulation (Van den Brink et al. 2018).

The genetic basis of anticoagulant resistance in rats (and rodents in general) is the presence of point mutations in the three exons of the Vitamin K Epoxide Reductase Complex Subunit 1 (VKORC1) gene. The result is a few VKORC1 amino acid changes (Rost et al. 2004). Pelz et al. (2005) first described eight mutations in the VKORC1 gene of brown rats, five of which were related to aminoacidic positions 128 and 139. Grandemange et al. (2009) then demonstrated that such mutations conferred resistance to firstgeneration anticoagulants. To date, approximately 30 mutations have been described in the VKORC1 of several Rattus species worldwide (Goulois et al. 2016; Iacucci et al. 2018; Pelz et al. 2005; Rost et al. 2009; Tanaka et al. 2012).

The spread of invasive rodent species has strongly affected the entire Mediterranean area, especially insular ecosystems regarded as hotspots of endemic fauna and flora. In particular, the black rat Rattus rattus, classified as one of the world's worst invasive species, strongly impact on many natural habitats worldwide (Capizzi et al. 2014; Lowe et al. 2000). A number of eradication programs targeting invasive rodent species have been conducted to restore natural habitats in several western Mediterranean islands (e.g. Molara, Tavolara, Linosa, Pianosa, Montecristo, reviewed in Capizzi et al. 2016). The present study is itself part of a comprehensive habitat restoration and conservation of endemic plant and animal species program implemented in the Pontine Archipelago (http://www.ponderat.eu/en-home, Celesti-Grapow et al. 2017). 
We investigated sequence polymorphisms at the three exons of the VKORC1 gene in 119 black rats from Latium mainland and the Pontine Archipelago (Central Italy) to check for the occurrence of sequence variants conferring resistance to anticoagulants. While resistant phenotypes of brown rats and mice have been recently recorded in Italy (Iacucci et al. 2018; Iannucci et al. 2019), this is the first investigation of its kind on black rats in mainland Italy and nearby islands. We also assessed patterns of genetic diversity and population structure at 10 microsatellite loci in order to define the eradication units of black rats occurring in the Pontine Archipelago and describe the likely routes of colonization. The identification of such eradication units (defined as "the interconnected populations that must be eradicated at the same time to prevent rapid recolonization", sensu Robertson and Gemmell 2004) is, in fact, a quite important parameter to consider when planning an eradication plan. Finally, we evaluated the presence and prevalence of pathogens, with particular reference to those transmissible to humans, by analyzing a subsample of 38 black rats. As a whole, this study provides background information to help successful eradication of black rats in the Pontine Archipelago, limit the risks for human and animal health and devise biosecurity measures to prevent reinvasion.

\section{Materials and methods}

Study area, sample collection and DNA extraction

The Pontine Archipelago is a group of five volcanic islands, including Ponza, Palmarola, Ventotene, Santo Stefano and Zannone, located off the western coast of Central Italy (Fig. 1). The Archipelago is a popular

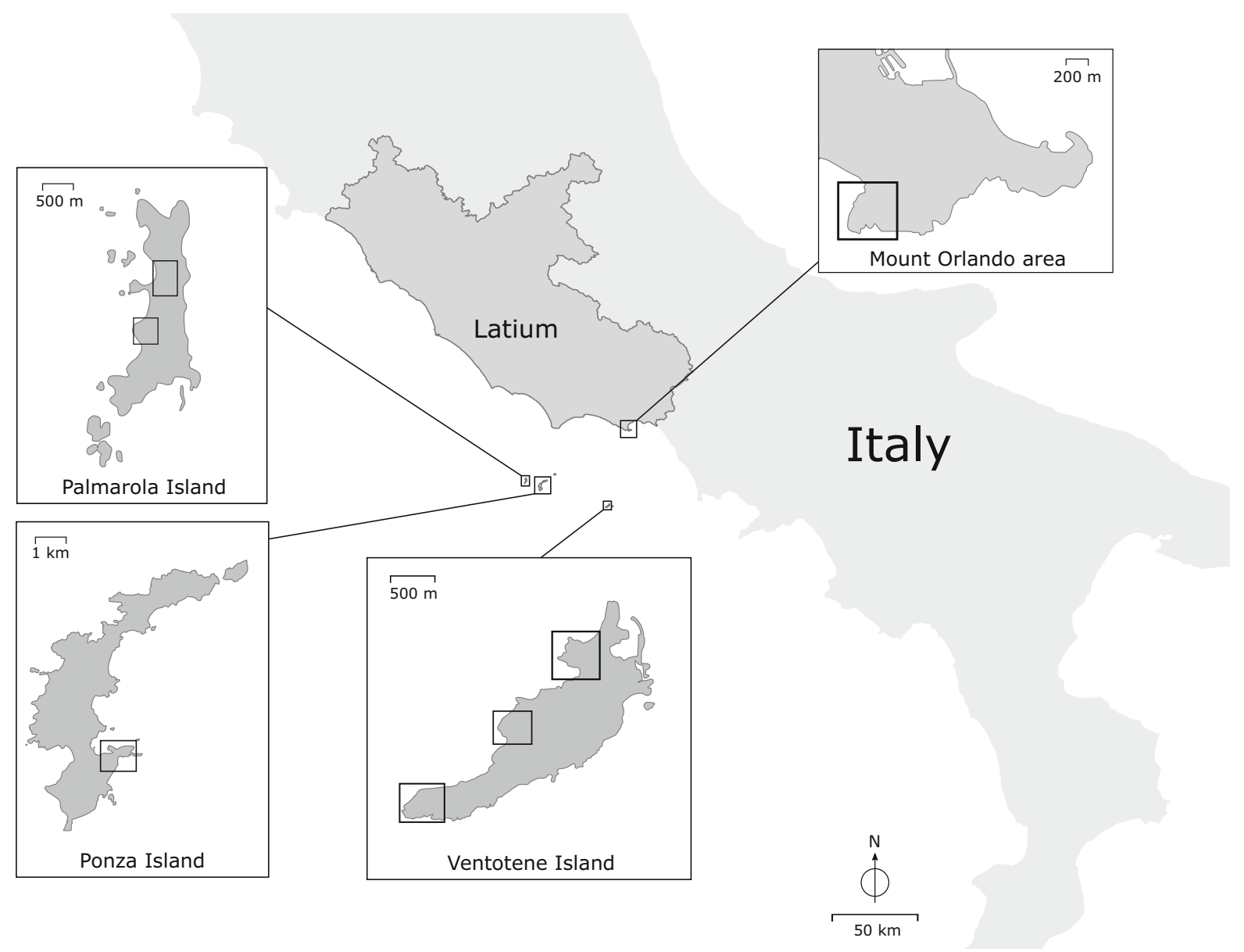

Fig. 1 Map of the study sites. Black rats were sampled on the islands of Palmarola (PLM), Ventotene (VNT), Mount Orlando (MNO), and Ponza (PNZ). Samples for epidemiological investigations were collected in PLM, VNT and PNZ 
touristic destination in summer. In winter, on the other hand, some islands are uninhabited. Zannone is part of the Circeo National Park, while the other islands are included in the European Natura 2000 network.

We trapped a total of $119 R$. rattus on the islands of Palmarola $(N=36)$, Ventotene $(N=49)$ and Ponza $(N=10)$, and in mainland Italy on the nearby Mount Orlando $(N=24)$. Mount Orlando rise close to the Gaeta and Formia harbours, from where ships depart to reach Ponza and Ventotene. Private and tourist boats depart daily from Ponza to the other Pontine islands. On Ponza Island, rats were trapped from the main harbour.

Approximately $10-50 \mathrm{mg}$ of tail muscle tissue was collected from each rat and preserved in absolute ethanol. DNA was extracted by overnight digestion at $55^{\circ} \mathrm{C}$ in a lysis buffer with proteinase $\mathrm{K}$, followed by isopropanol-ethanol precipitation (Sambrook and Russell 2001). Samples were then resuspended in DNAase-free water and preserved at $-80{ }^{\circ} \mathrm{C}$.

Genetic analyses

The VKORCl gene was amplified by polymerase chain reaction (PCR) using three sets of primer pairs designed to anneal to the adjacent intronic regions. The first two sets of primers were specifically designed for this study to amplify exon 1 and 2, respectively. Primer sequences were VKORC1_ex1_F: 5'TCTTCCCTCCTGTSYCTGGG-3' and VKORC1_ex1_R: 5'-AAATYATCTGGYAACCTGGC-3' for exon 1, and VKORC1_ex2_F: 5'-GGTGGMGCT TCTTGCTAATC-3' and VKORC1_ex2_R: 5'GCTCAGTAATTAGCAGCTGGC-3' for exon 2 . Exon 3 was amplified using primers VKORC1_ex3_F: 5'-TTTCACCAGAAGCACCTGCTGYC- $3^{\prime}$ and VKORC1_ex3_R: 5'-ACACTTGGGCAAGGSTCATGTG- $3^{\prime}$ both modified from Grandemange et al. (2009).

PCR amplifications were performed in $10 \mu \mathrm{l}$ total reaction using $1 \mathrm{X}$ reaction buffer, $300 \mu \mathrm{M}$ dNTPs, $1.5 \mathrm{mM} \mathrm{MgCl}_{2}, 0.5 \mu \mathrm{M}$ of each primer and $0.5 \mathrm{U}$ Taq DNA polymerase (Invitrogen). Thermal profiles consisted of an initial denaturation step of $5 \mathrm{~min}$ at $94{ }^{\circ} \mathrm{C}$, followed by 35 cycles of $45 \mathrm{~s}$ at $94{ }^{\circ} \mathrm{C}$, annealing for $45 \mathrm{~s}$ at $52-54{ }^{\circ} \mathrm{C}$, extension for $90 \mathrm{~s}$ at $72{ }^{\circ} \mathrm{C}$, and a final extension step for $10 \mathrm{~min}$ at $72{ }^{\circ} \mathrm{C}$. Amplicons were visualized on a $1 \%$ agarose gel, purified using Sure Clean (Bioline) and cycle-sequenced using
BigDye Terminator v3.1 chemistry (Life Technologies). Sequencing products were isopropanol-precipitated and resolved by capillary electrophoresis in an Applied Biosystems 3130xl Genetic Analyzer.

Allelic variation at 10 microsatellite loci was determined using primers described for $R$. norvegicus by Jacob et al. (1995) (D10Rat20, D5Rat83, D7Rat13, D19Mit2, D11Mgh5, D16Rat81 and D9Rat13) and for $R$. fuscipes greyii by Hinten et al. (2007) (RfgL3, RfgG3 and RfgD6) and successfully tested in $R$. rattus by Savidge et al. (2012), Ragionieri et al. (2013), Willows-Munro et al. (2016) and Iannucci et al. (2018). Each locus was PCR-amplified in $10 \mu \mathrm{l}$ total reaction volume using $1 \mathrm{X}$ reaction buffer, $1.5 \mathrm{mM}$ of $\mathrm{MgCl}_{2}, 0.5 \mu \mathrm{M}$ of each primer, $200 \mu \mathrm{M}$ of each dNTP and $0.5 \mathrm{U}$ of Taq DNA polymerase (Invitrogen). Thermal profiles consisted of an initial denaturation step of $5 \mathrm{~min}$ at $94{ }^{\circ} \mathrm{C}, 35$ cycles of $60 \mathrm{~s}$ at $94{ }^{\circ} \mathrm{C}$, annealing for $45 \mathrm{~s}$ at $54-57{ }^{\circ} \mathrm{C}$ and extension for $60 \mathrm{~s}$ at $72{ }^{\circ} \mathrm{C}$, and a final extension for $7 \mathrm{~min}$ at $72{ }^{\circ} \mathrm{C}$. PCR products were then pooled into three multilocus sets: R1 including D10Rat20, D5Rat83, D7Rat13 and D19Mit2, R2 including D11Mgh5, D16Rat81 and D9Rat13, and R3 including RfgL3, RfgG3 and RfgD6. Amplicons were resolved by capillary electrophoresis in an Applied Biosystems 3130xl Genetic Analyzer and allele sizes scored against a GeneScan500 LIZ size standard using GeneMapper 5.0 (Applied Biosystems).

Epidemiological investigations

Whole DNA was extracted from spleen $(\approx 10 \mathrm{mg})$, skeletal muscle ( $\approx 25 \mathrm{mg}$ of quadriceps femoris), kidney $(\approx 25 \mathrm{mg})$ and the central nervous system (CNS) ( $\approx 25 \mathrm{mg}$ of brain homogenate) of a subsample of 15 female and 23 male adult and young black rats (Palmarola, $\mathrm{n}=13$; Ventotene, $\mathrm{n}=18$; Ponza, $\mathrm{n}=7$ ) using the GenElute Mammalian Genomic MiniPrepKit (Sigma Aldrich, MO, USA) following the manufacturer's instructions.

A 145 bp fragment of Leishmania infantum kinetoplast DNA (kDNA) was amplified from spleen samples using the mRV1-mRV2 primer pair and the PCR amplification conditions reported in Zanet et al. (2014a). Spleen samples were also tested in order to detect tick-borne pathogens. Specifically, a $400 \mathrm{bp}-$ long fragment of the V4 hypervariable region of the $18 \mathrm{~S}$ rDNA of protozoa of the genera Babesia and 
Theileria was amplified according to Zanet et al. (2014b). A 452 bp-long fragment of the 16 s rRNA gene of bacteria of the genera Anaplasma and Ehrlichia was amplified using primers PER1 and PER2 as reported by Beninati et al. (2006). Borrelia burgdorferi sensu lato was detected by PCR amplification of a $452 \mathrm{bp}$ fragment of the 5S-23S intergenic spacer region using the 23SN1-23SC1 primer pair (Rijpkema et al. 1995). Skeletal muscle, kidney and CNS were tested in parallel to detect the presence of Toxoplasma gondii using a Loop-Mediated Isothermal Amplification (LAMP) as reported in Trisciuoglio et al. (2015). Positive and negative control samples were included in each PCR/LAMP assay and standard precautions were taken to avoid contamination. PCR positive samples were purified and cycle-sequenced as described above. Species identification was performed by comparison with sequences available in GenBank using MEGA X (Kumar et al. 2018).

Statistical analysis

\section{VKORC1 gene sequence variation}

The VKORC1 sequences were edited using Geneious 8.0.5 (Kearse et al. 2012). Single nucleotide polymorphisms (SNPs) were identified by comparison with annotated reference sequences downloaded from GenBank.

\section{Microsatellites variation}

Microsatellite alleles were checked for scoring errors due to stuttering, allele dropout and evidence of null alleles using Microchecker 2.2.3 (Van Oosterhout et al. 2004). All populations showed heterozygote deficiencies at loci D10Rat20 and RfgG3. Since our analysis indicated the occurrence of null alleles, we used the software FreeNA (www.montpellier.inra.fr/ URLB) to calculate allele frequencies corrected for null alleles following the INA method described in Chapuis and Estoup (2006). The new dataset was then used for subsequent analyses of population genetic variability.

The number of alleles and allelic richness for each locus and population were calculated using FSTAT 2.9.3.2 (Goudet 1995). Linkage equilibrium among loci and Hardy-Weinberg equilibrium (HWE) were assessed for each population using GENEPOP 4.2.1
(Rousset 2008). Significance levels were adjusted for multiple tests by using a sequential Bonferroni correction (Rice 1989). Statistical significance of deviation from HWE equilibrium was evaluated after 10,000 allele permutations performed in Genetix 4.05 (Belkhir et al. 1996-2004).

\section{Population divergence, genetic structure and gene flow}

We assessed whether individuals from a sampling site were more related than individuals from different sampling sites by comparing the mean pairwise relatedness calculated among individuals for each sampling site to average relatedness estimated across sampling sites using the Lynch and Ritland (1999) estimator implemented in GenAlex 6.5 (Peakall and Smouse 2006). Statistical significance was obtained after 10,000 permutations of genotypes.

Genetic divergence among sampling sites was estimated by the exact test for population differentiation implemented in GENEPOP 4.6 (Rousset 2008). Significance values were calculated using a Markov chain with 10,000 batches and 10,000 iterations per batch combined over loci using the Fisher method. Genetic differentiation was also assessed by the $F_{\text {ST }}$ estimator $\theta$ using ARLEQUIN 3.5 (Excoffier and Lischer 2010). Statistical significance of $\theta$ values under the null hypothesis of no differentiation among sampling sites was assessed after 10,000 allele permutations.

Genetic structure was investigated using three clustering techniques: a multivariate discriminant analysis of principal components (DAPC, Jombart et al. 2010), a method based on sparse non-negative matrix factorization algorithms (snmf, Frichot and François 2015; Frichot et al. 2014) and a Bayesian clustering approach implemented in STRUCTURE 2.3.4 (Pritchard et al. 2000).

The DAPC analysis was performed using ADEGENET version 1.2.8 (Jombart and Collins 2015) in the $\mathrm{R}$ statistical environment $\mathrm{R}$ 3.5.1. The optimal number of genetic clusters $K$ describing the data was identified using Bayesian information criterion (BIC) scores and the "find.clusters" function. In this analysis, the optimal $K$ is expected to be associated with a low BIC score positioned along the BIC curve where the following BIC scores either increase or are only slightly lower than the chosen BIC value (Jombart 
et al. 2010). We determined the optimal number of principal components (PCs) for the DAPC by crossvalidation using the "xvalDapc" function with 1,000 replicates. We selected the number of PCs associated to the lowest root mean squared error value. We ran DAPC using all the available discriminant functions and calculated the assignment probability of individuals to each cluster, which were graphically visualized using ADEGENET (Jombart and Collins 2015).

Snmf was run using the "snmf" function of the R package LEA (Frichot and François 2015). The entropy criterion values were used to choose the number of ancestral populations $K$ that best explained the genotypic data (i.e. the $K$ value with minimal cross-entropy or for which the cross-entropy curve reached a plateau). We tested $K=1-6$ using 100 replicates for each $K$. Robustness of snmf to the regularization parameter (alpha) was assessed by running preliminary analyses with alpha $=1,10$, 100 , and 1,000 . The best entropy scores were obtained with alpha $=100$. The best $K$ was determined by the run with the lowest entropy value (Frichot et al. 2014). The Q-matrix computed from the snmf run was graphically visualized in a bar chart representation using the "barchart" function.

The Bayesian clustering method implemented in STRUCTURE 2.3.4 was used to infer the most likely number of genetically distinct clusters (populations) given the observed genotypes and to evaluate the proportion of each individual's genotype belonging to each inferred population. We used the admixture model as the most appropriate for populations that may have recent ancestors from more than one population. We run 1,000,000 Markov Chain Monte Carlo (MCMC) iterations without prior population information for a number of populations $K$ ranging from 1 to 6 using a burn-in period of 20,000 iterations. We calculated the mean likelihood over 20 runs for each $K$ with correlated allele frequencies and estimated the most likely number of clusters as described in Evanno et al. (2005). The $K$ value with the highest $\Delta K$ was then used as prior information to estimate the proportion of membership of each genotype in each of the $K$ populations. Results were graphically visualized using STRUCTURE PLOT (Ramasamy et al. 2014).

We also estimated recent migration rates using BayesAss 1.3 (Wilson and Rannala 2003). This Bayesian approach relies on MCMC to estimate the proportion of migrants in a population over the last few generations. The run consisted of $3 \times 10^{6}$ iterations with a sampling frequency of 2,000 and the first $1 \times 10^{6}$ steps discarded. We used default setting delta values.

\section{Demographic inference}

Evidence of bottleneck in the four $R$. rattus sampling sites was assessed using BOTTLENECK 1.2.02 (Cornuet and Luikart 1996). Populations that have experienced a recent reduction in their effective population size are expected to exhibit a corresponding reduction in the number of alleles and gene diversity (Piry et al. 1999). The average gene diversity expected at equilibrium was calculated from a distribution of 10,000 simulated values under the two-phase mutation model (TPM) and the stepwise mutation model (SMM) of microsatellite evolution. For the TPM, we set 70 multistep mutations with a $12 \%$ variance among multi-steps (Piry et al. 1999), and obtained statistical significance based on 1,000 replications. Gene diversity excess was assessed using a Wilcoxon sign-rank test (Luikart et al. 1998). We also assessed whether the observed allele frequencies at each locus deviated from an L-shaped distribution expected under mutation-drift equilibrium (Luikart et al. 1998). A similar test was performed by calculating the Garza and Williamson (2001) index (M) to test for a reduction in rat population size using ARLEQUIN 3.5. Garza and Williamson (2001) reported that $\mathrm{M}$ values greater than 0.82 should be representative of stable populations that have not suffered a known reduction in size, whereas values of the $\mathrm{M}$ index lower than 0.68 indicate a bottleneck or a founder event.

\section{Epidemiological investigations}

Variables associated with infection of each pathogen were identified using generalized linear models with PCR results as dichotomous response variables in $\mathrm{R}$ 3.5.1.

\section{Results}

VKORC1 gene sequence variation

We amplified and sequenced three fragments of the VKORCl gene $253 \mathrm{bp}, 272 \mathrm{bp}$ and $308 \mathrm{bp}$ long, 
Table 1 VKORC1 mutations found in Rattus rattus from the Pontine Archipelago and Latium mainland

\begin{tabular}{llllll}
\hline Mutations & Exon & WT codon & Mut codon & WT AA & Mut AA \\
\hline A41A & 1 & GCG & GCA & Ala & Ala \\
L97L & 2 & TTA & CTA & Leu & Leu \\
S110S & 3 & TCC & TCT & Ser & Ser \\
A143A & 3 & GCG & GCA & Ala & Ala \\
\hline
\end{tabular}

WT codon, wild-type codon; Mut codon, mutated codon; WT AA, wild-type amino acid; Mut AA, mutated amino acid

Table 2 Genetic diversity measures in R. rattus from four sampling sites in the Pontine Archipelago and Latium mainland

\begin{tabular}{lllllll}
\hline Sampling site & $N$ & $N a$ & \multicolumn{1}{l}{$A_{R}$} & $A p$ & $H o$ & $H e$ \\
\hline Mount Orlando & 24 & $7.0 \pm 0.61$ & $5.5 \pm 0.34$ & 19 & $0.67 \pm 0.05$ & $0.63 \pm 0.04$ \\
Palmarola & 36 & $7.3 \pm 0.94$ & $5.04 \pm 0.55$ & 15 & $0.53 \pm 0.07$ & $0.52 \pm 0.07$ \\
Ventotene & 49 & $6.7 \pm 0.73$ & $5.10 \pm 0.46$ & 13 & $0.65 \pm 0.05$ & $0.64 \pm 0.05$ \\
Ponza & 10 & $6.5 \pm 0.75$ & $6.29 \pm 0.69$ & 7 & $0.66 \pm 0.09$ & $0.66 \pm 0.08$ \\
\hline
\end{tabular}

$N$, number of analysed individuals; $N_{A}$, number of alleles; $A_{\mathrm{R}}$, allelic richness; $A_{\mathrm{P}}$, number of private alleles; $H_{\mathrm{O}}$, observed heterozygosity; $H_{\mathrm{E}}$, expected unbiased heterozygosity. Mean \pm SE values

respectively. These allowed analysis of the entire 160 amino acids encoding region of the gene. We found a total of 4 SNPs, of which one in exon 1 , one in exon 2 and two in exon 3 (Table 1). All were silent mutations.

Population genetic diversity

No significant linkage disequilibrium was recorded across either populations or loci. All loci were polymorphic, with a number of alleles ranging from 4 (locus RfgD6) to 20 (locus D7Rat13) (Table A1, Supporting Information). Relatively high levels of genetic variation were recorded at all sampling sites (Table 2). Allelic diversity and average allelic richness were similar across sampling sites, ranging from $6.50 \pm 0.75 \mathrm{SE}$ to $7.30 \pm 0.94 \mathrm{SE}$ and from $5.04 \pm 0.55 \mathrm{SE}$ to $6.29 \pm 0.69 \mathrm{SE}$, respectively (Table 2, Table A1, Supporting Information). The total number of private alleles ranged from 7 to 19 with the highest number assessed in the Mount Orlando sampling site. The lowest values of expected and observed heterozygosity were recorded in Palmarola (Table 2, Table A1, Supporting Information). No deviation from HWE was recorded after Bonferroni correction, except for Palmarola at locus RfgD6 (Table A1, Supporting Information).

Average pairwise relatedness was $r=0.074$ for Mount Orlando, $r=0.103$ in Palmarola, $r=0.076$ in Ventotene and $r=0.076$ in Ponza. All values were
Table 3 Pairwise comparison matrix of the $F_{\mathrm{ST}}$ estimator $\theta$ between black rat sampling sites (below diagonal) and corresponding $P$ values (above diagonal)

\begin{tabular}{lllll}
\hline & $\begin{array}{l}\text { Mount } \\
\text { Orlando }\end{array}$ & Palmarola & Ventotene & Ponza \\
\hline Mount & - & $<0.001$ & $<0.001$ & $<0.001$ \\
Orlando & & & & \\
Palmarola & 0.34 & - & $<0.001$ & $<0.001$ \\
Ventotene & 0.19 & 0.31 & - & $<0.001$ \\
Ponza & 0.22 & 0.22 & 0.17 & - \\
\hline
\end{tabular}

Significant $P$ values $<0.008$ after Bonferroni correction

significantly higher than average relatedness calculated among all individuals across locations $(r=-0.004 \pm 0.001 \mathrm{SE}, P<0.001)$.

Population divergence and genetic structure

The Fisher exact test rejected the hypothesis of genetic homogeneity of allele frequency distributions $\left(X^{2}=\infty, d f=20, P<0.001\right)$. Significant genetic differentiation was also recorded by $F$-statistics among populations $(\theta=0.27, P<0.001)$ and for all pairwise population comparisons (Table 3 ). Migration rates between localities were very low and varied between 0.004 and 0.012. On the other hand, proportion of self-recruitment in each site was always higher than 0.95 (Table 4). 
Table 4 Mean $( \pm$ SE) and 95\% confidence intervals (in parentheses) of Bayesian posterior distribution of recent migration rates of $R$. rattus between sampling sites

Bold values along the diagonal axis represent the proportion of resident individuals in each site

\begin{tabular}{lllll}
\hline & From & & \\
\cline { 2 - 5 } & Mount Orlando & Palmarola & Ventotene & Ponza \\
\hline To & & & & \\
Mount Orlando & $\mathbf{0 . 9 8 7} \pm \mathbf{0 . 0 1 3}$ & $0.003 \pm 0.004$ & $0.002 \pm 0.003$ & $0.012 \pm 0.016$ \\
& $(\mathbf{0 . 9 5 4 - 1 . 0 0 )}$ & $(0.000-0.017)$ & $(0.000-0.011)$ & $(0.000-0.057)$ \\
Palmarola & $0.004 \pm 0.007$ & $\mathbf{0 . 9 9 1} \pm \mathbf{0 . 0 0 8}$ & $0.002 \pm 0.004$ & $0.011 \pm 0.015$ \\
& $(0.000-0.023)$ & $(\mathbf{0 . 9 6 8}-\mathbf{1 . 0 0})$ & $(0.000-0.012)$ & $(0.000-0.056)$ \\
Ventotene & $0.004 \pm 0.006$ & $0.003 \pm 0.004$ & $\mathbf{0 . 9 9 3} \pm \mathbf{0 . 0 0 7}$ & $0.025 \pm 0.025$ \\
& $(0.000-0.023)$ & $(0.000-0.015)$ & $(\mathbf{0 . 9 7 2}-\mathbf{1 . 0 0})$ & $(0.000-0.091)$ \\
Ponza & $0.004 \pm 0.006$ & $0.003 \pm 0.004$ & $0.002 \pm 0.004$ & $\mathbf{0 . 9 5 0} \pm \mathbf{0 . 0 3 5}$ \\
& $(0.000-0.021)$ & $(0.000-0.016)$ & $(0.000-0.014)$ & $(\mathbf{0 . 8 6 4 - 0 . 9 9 6 )}$ \\
\hline
\end{tabular}

The DAPC analysis suggested the presence of three distinct genetic clusters (Fig. 2), as indicated by a rapid decrease of the $\mathrm{BIC}$ values from $\mathrm{K}=1$ to $\mathrm{K}=3$ and a further decrease for K $>3$ (Fig. A1, Supporting
Information). Individuals from Palmarola, Ventotene and Mount Orlando were all assigned to three different clusters (1, 2 and 3 respectively), while individuals from Ponza were partitioned among cluster $1(80 \%)$

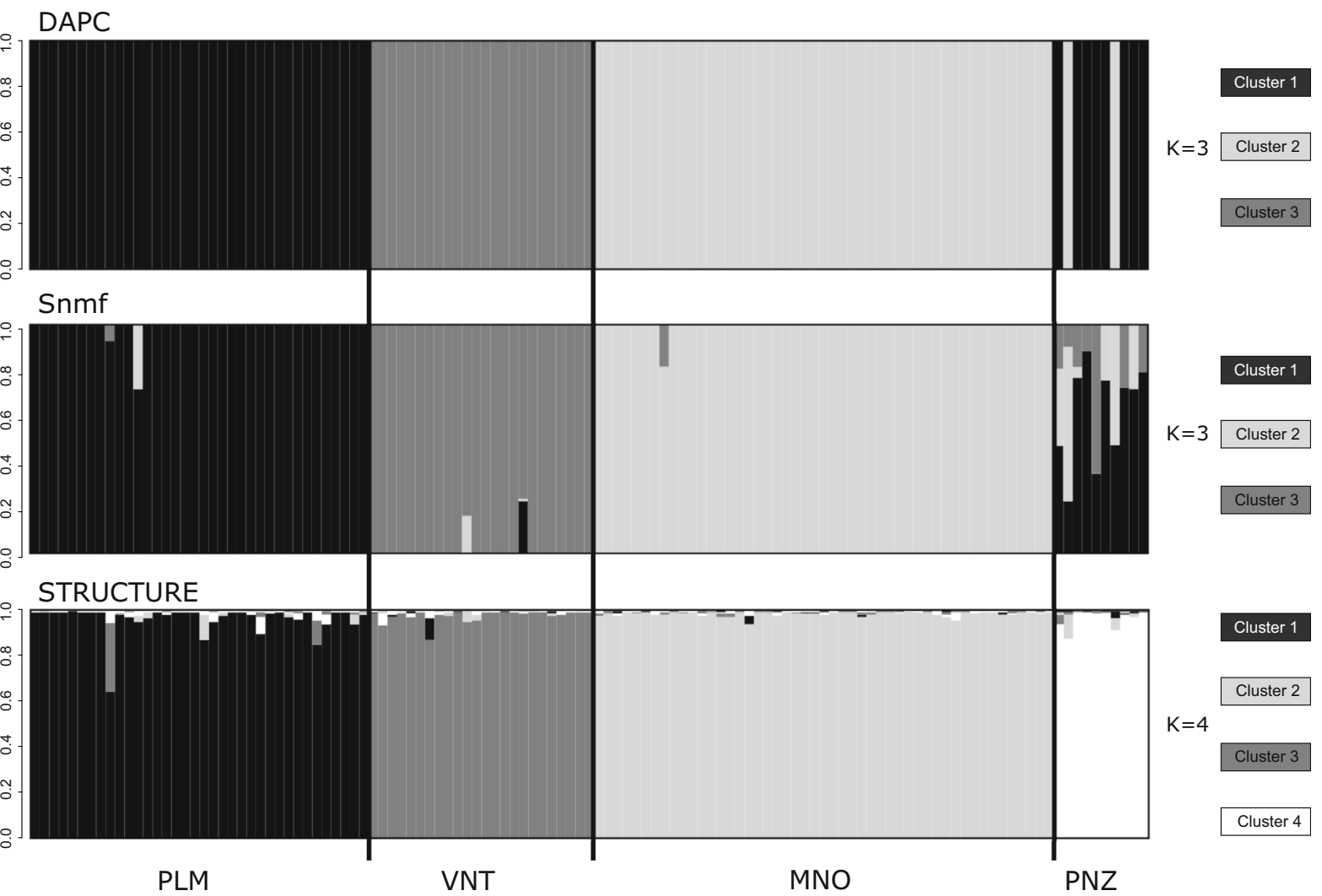

Fig. 2 Clustering analyses for 119 black rats performed using a multivariate discriminant analysis of principal components (DAPC), a method based on sparse nonnegative matrix factorization algorithms (snmf) and a Bayesian clustering approach (STRUCTURE). Each individual is represented by a vertical line partitioned into $K$ segments with lengths corresponding to the proportion of its genome originating from each of the $K$ inferred clusters. Black vertical bars define distinct island sampling sites. Location acronyms as in Fig. 1 
and 2 (20\%, Fig. 2; Fig. 3a, b). Absence of overlap among genetic clusters in the ordination plot indicated a high degree of differentiation (Fig. 3c).

Snmf results were concordant with the DAPC analysis. The most likely number of clusters based on the value of $K$ with the minimal cross-entropy value was $K=3$ (Fig. A1, Supporting Information). Individuals from Palmarola, Mount Orlando and Ventotene were assigned to cluster $3(99 \%)$, cluster 2 (96\%) and cluster 1 (98\%) respectively. The Ponza sampling site was admixed, with $11 \%$ of individuals assigned to cluster $1,21 \%$ to cluster 2 and $68 \%$ to cluster 3 (Fig. 2).

The Bayesian population structure analysis revealed that the most probable number of clusters for interpreting the observed genotypes was $K=4$ based on the highest modal value of $\Delta K=521.79$ estimated using the Evanno et al. method (Fig. A1, Supporting Information). Four main partitions were used as prior population information for calculating the posterior probability of individual assignment (Fig. 2). Individuals from Mount Orlando were almost entirely assigned to cluster $4(97.5 \%)$, those from Palmarola to cluster $2(98.4 \%)$, Ventotene to cluster 1 (96.2\%) and Ponza to cluster 3 (96\%).

\section{Demographic inference}

The heterozygosity excess approach performed under the stepwise and two-phase models of microsatellite mutation reported no evidence of reduction in effective population size (Table 5). The Palmarola black rat population showed evidence of heterozygosity deficiency under the stepwise model of microsatellite. Moreover, all four locations had a clear L-shaped allele frequency distribution. On the other hand, the $\mathrm{M}$ ratio index varied from 0.22 to 0.26 suggesting a bottleneck event in all island populations. The highest $M$ values were recorded for black rats from Palmarola (Table 5).

\section{Epidemiological investigations}

The 38 rats tested for zoonotic pathogens had an average weight of $162.98 \mathrm{gr}$ ( $\pm 7.60 \mathrm{gr})$. All animals appeared to be in satisfactory body conditions and no gross lesions were reported at necropsy.

Leishmaina infantum DNA was detected in the spleen of two females from Ventotene Island with a prevalence of 5.26\% (CI 95\% 1.46-17.29\%). Babesia piroplasms were detected in 14 rats, corresponding to $36.84 \%$ (CI 95\% 23.38-52.72\%) of the tested animals. No significant difference was recorded in infection prevalence among sexes, age classes or islands of origin (Table 6). All isolates were sequenced and identified to the species level as B. microti. Borrelia afzelii DNA was amplified from an adult female rat from Ventotene. This rat was also infected by $B$. microti. None of the rats analysed resulted positive to Anaplasma/Ehrlichia spp. Theileria gondii DNA was detected with a prevalence of $42.11 \%$ (IC 95\% $27.85-57.81 \%$ ). Fifteen rats tested positive on muscle-extracted DNA and one on kidney-extracted DNA. A relatively high infection prevalence was recorded in rats from Palmarola $(P=46.15 \%$, CI $95 \%$ 23.21-70.86\%, $P>0.05)$. However, no significant difference was recorded in infection prevalence among sexes, age classes or island of origin (Table 6).

\section{Discussion}

VKORC1 sequence variation

In this study, we recorded no black rats from the Pontine islands carrying mutations in subunit 1 of the VKORCl gene known to confer resistance to common anticoagulants. To date, about 30 such mutations have been detected in $R$. norvegicus (Pelz et al. 2005; Rost et al. 2009), while only six were reported for $R$. rattus (Goulois et al. 2016; Tanaka et al. 2012). In Europe, resistance to rodenticides is frequently observed in $R$. norvegicus, but very rarely in $R$. rattus, probably because of the lower number of studies performed on black rats. Only recently, Goulois et al. (2016) detected the first mutation (Y25F) in the VKORC1 gene of $R$. rattus in Spain and suggested an association to resistance to bromadiolone. However, this newly discovered mutation was not found in our sample set.

We detected only five synonymous mutations in the VKORCl coding sequence, suggesting that resistance to anticoagulants in $R$. rattus had not yet affected our study area. However, the extensive use of anticoagulants (second-generation compounds such as bromadiolone and difenacoum, in particular) as pest control in the Pontine Archipelago has been shown to exert selective pressure on VKORC1, resulting in resistance in house mice as shown by Iannucci et al. (2019). For 
Fig. 3 Assignment of Rattus rattus to population of origin based on DAPC analysis. a The number of individuals from each population (vertical axis) assigned to each of the three inferred genetic clusters (horizontal axis). The size of black squares is proportional to the number of individuals assigned to each cluster (upper legend).

b Assignment based on discriminat functions of individuals (vertical axis) to each genetic cluster determined by K-means analysis. Thick horizontal lines show the proportion of each multilocus genotype belonging to one or more clusters. Bullets indicate the cluster where individuals were originally assigned by $\mathrm{K}$-means analysis.

c Ordination plot for the first two discriminant axes. Dots represent individual rats connected to the centre of an inertia ellipsis, which indicates assignment to one of the three genetic clusters inferred by DAPC. The upper-left inset shows the variance explained by the principal component axes used for DAPC (in dark grey). The upper-right inset shows in relative magnitude the variance explained by the two discriminant axes. Location acronyms as in Fig. 1
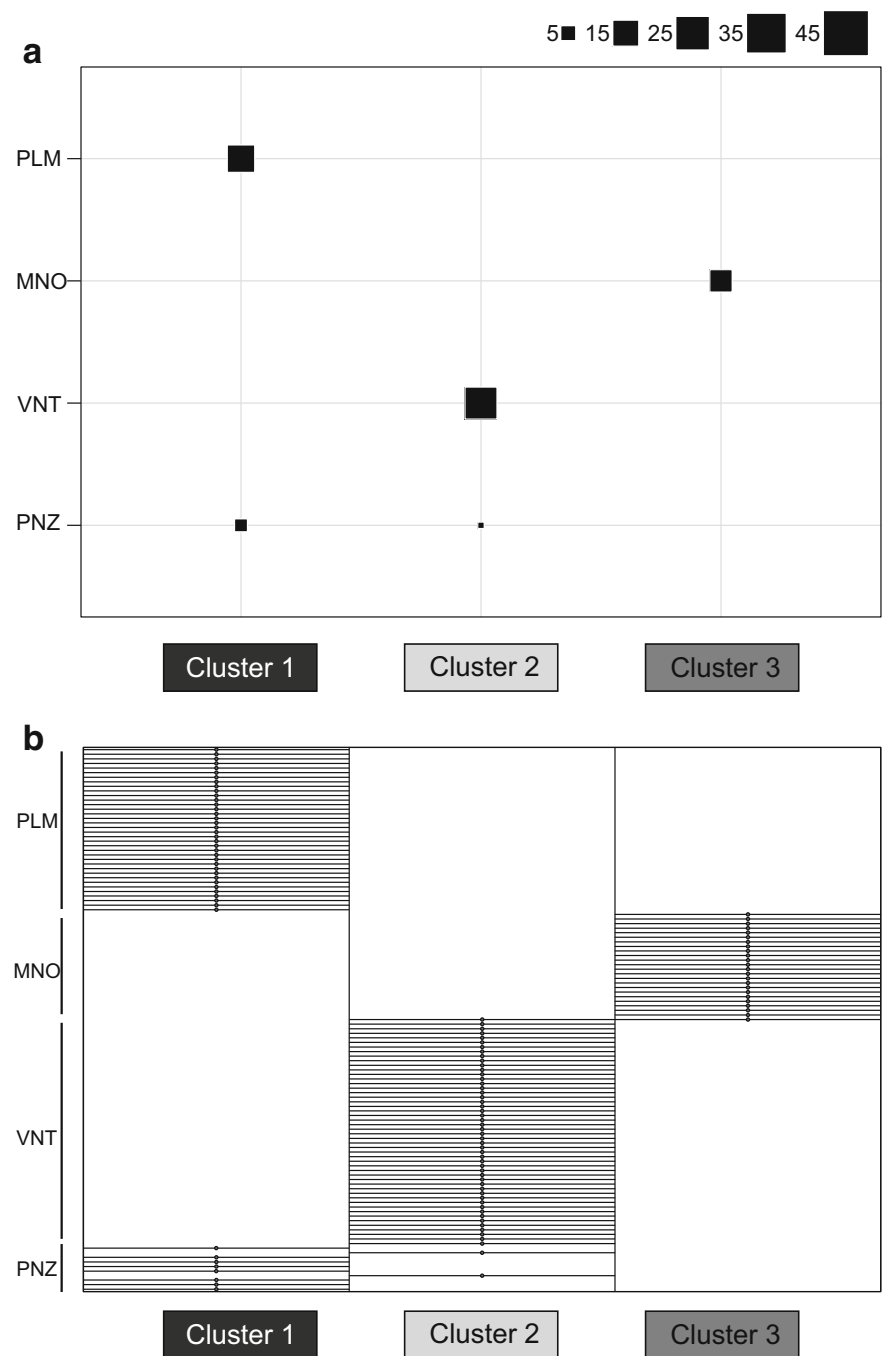

C

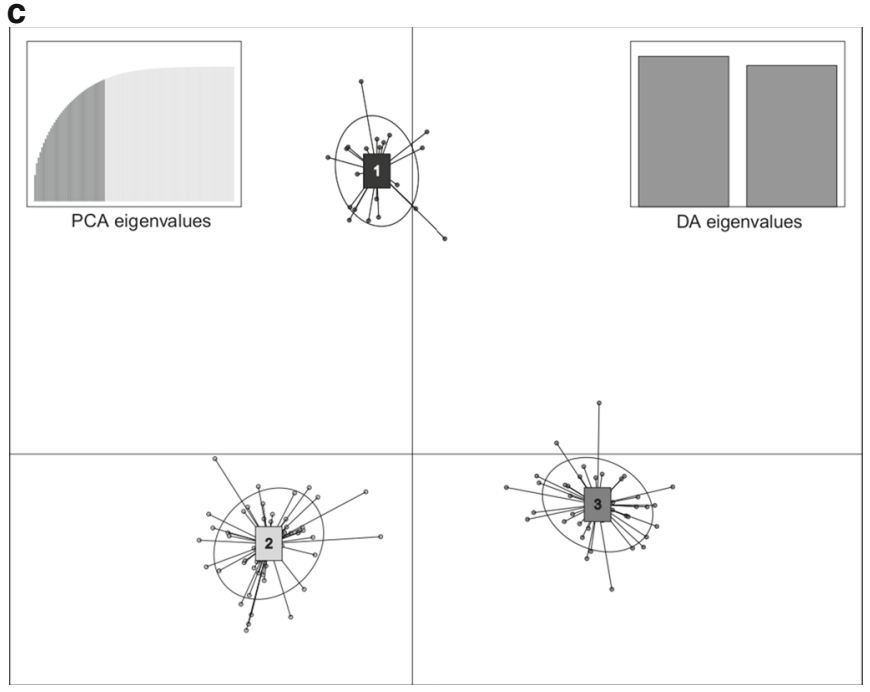


Table 5 Results of the heterozygosity excess and M-ratio tests performed to assess evidence of population bottleneck in black rats from Mount Orlando and the Pontine Islands

\begin{tabular}{|c|c|c|c|c|c|c|c|c|}
\hline \multirow[t]{3}{*}{ Location } & \multicolumn{6}{|c|}{ Heterozygosity excess test } & \multirow{2}{*}{\multicolumn{2}{|c|}{ M-ratio test }} \\
\hline & \multicolumn{3}{|l|}{ TPM } & \multicolumn{3}{|c|}{ SMM } & & \\
\hline & $N_{\text {exc }}$ & Ratio & $P_{\mathrm{TPM}}$ & $N_{\text {exc }}$ & Ratio & $\mathrm{P}_{\mathrm{SSM}}$ & Mode & M-ratio \\
\hline Mount Orlando & 5.96 & $5: 5$ & 0.54 & 5.92 & $9: 1$ & 0.99 & L-shaped & 0.22 \\
\hline Palmarola & 5.90 & $5: 5$ & 0.65 & 5.91 & $8: 2$ & 0.99 & L-shaped & 0.26 \\
\hline Ventotene & 5.95 & $2: 8$ & 0.08 & 5.94 & $8: 2$ & 0.98 & L-shaped & 0.24 \\
\hline Ponza & 5.95 & $4: 6$ & 0.38 & 6.20 & $5: 5$ & 0.68 & L-shaped & 0.24 \\
\hline
\end{tabular}

TPM, two-phase model of microsatellite mutation; SMM, stepwise model of microsatellite mutation; $N_{\text {exc }}$, expected number of loci with heterozygosity excess under mutation-drift equilibrium; Ratio, number of microsatellite loci exhibiting heterozygosity deficiency versus excess; $P_{\mathrm{TPM}}$ and $P_{\mathrm{SSM}}$ are probability values of the Wilcoxon test for heterozygote excess under the TPM and SMM models, respectively. Mode indicates a L-shaped normal distribution or a shifted distribution

Table 6 Number of black rats resulted positive to infections for each tested pathogen

\begin{tabular}{|c|c|c|c|c|}
\hline & \multicolumn{4}{|c|}{ Number of rats tested positive/total number of rats $(\%)$} \\
\hline & Toxoplasma gondii & Babesia microti & Borrelia afzelii & Leishmania infantum \\
\hline \multicolumn{5}{|c|}{ Island of origin } \\
\hline Ponza & $3 / 7(42.86 \%)$ & $2 / 7(28.57 \%)$ & $0 / 7(0.00 \%)$ & $0 / 7(0.00 \%)$ \\
\hline Ventotene & $7 / 18(38.89 \%)$ & $7 / 18(38.89 \%)$ & $1 / 18(5.56 \%)$ & $2 / 18(11.11 \%)$ \\
\hline Palmarola & $6 / 13(46.15 \%)$ & $5 / 13(38.46 \%)$ & $0 / 13(0.00 \%)$ & $0 / 13(0.00 \%)$ \\
\hline \multicolumn{5}{|l|}{ Age } \\
\hline Juvenile & $4 / 14(28.57 \%)$ & $3 / 14(21.43 \%)$ & $0 / 14(0.00 \%)$ & $0 / 14(0.00 \%)$ \\
\hline Adult & $12 / 24(50.00 \%)$ & $11 / 24(45.83)$ & $1 / 24(4.17 \%)$ & $2 / 24(8.33 \%)$ \\
\hline \multicolumn{5}{|l|}{ Sex } \\
\hline Male & $12 / 23(52.17 \%)$ & $7 / 23(30.43 \%)$ & $0 / 23(0.00 \%)$ & $0 / 23(0.00 \%)$ \\
\hline Female & $4 / 15(26.67 \%)$ & $7 / 15(46.67 \%)$ & $1 / 15(6.67 \%)$ & $2 / 15(13.33 \%)$ \\
\hline
\end{tabular}

this study, we sampled black rats from both sparsely populated islands (Palmarola) with no or very limited control activities, and populated areas (e.g. Ponza, Ventotene, and Mount Orlando) where rat control has been very intense over the last decades. It was therefore conceivable to record resistant phenotypes of black rats at least from areas where anticoagulants have been extensively used.

Anticoagulant resistance in Europe is much more common in the house mouse than in the genus Rattus (Goulois et al. 2017). This is because of a stronger selective pressure exerted on the house mouse by both first-generation rodenticides, commonly used in the last decades, and current second-generation anticoagulants (Goulois et al. 2017; Pelz and Prescott 2015). House mice control is mainly carried out by nonprofessionals, who tend to exceed in the use of rodenticides unaware of the consequences that a massive use of these molecules can have on the spread of resistance. On the contrary, rat control is usually performed by informed professionals, well aware of the risks associated with the use of such chemicals (Goulois et al. 2017).

\section{Definition of eradication units}

Allelic variation and heterozygosity values observed in black rats from the Pontine Archipelago were similar to those reported for other island systems (e.g. Abdelkrim et al. 2009; Iannucci et al. 2018; Ragionieri et al. 2013; Savidge et al. 2012). In all sites, relatedness coefficients were higher than average relatedness among individuals across sites. This may be due to the presence of family groups and inbreeding, as well as the occurrence of a founding event followed by limited gene flow (Frankham et al. 2010). 
We recorded a strong population structure and very limited gene flow among islands and mainland Mount Orlando. Differences in allele frequencies distribution, $F$-statistics, DAPC, snmf and Bayesian clustering analysis, all suggested that black rats from Palmarola and Ventotene are two distinct populations and should be therefore considered separate eradication units.

While STRUCTURE recorded the occurrence of four distinct clusters each corresponding to one of the sampling sites, the DAPC and snmf analyses showed a strong degree of admixture of rats from Ponza Island with individuals from Palmarola and Ventotene. These contrasting results can be due to different methodological approaches. STRUCTURE relies on the assumptions of absence of genetic drift as well as Hardy-Weinberg and linkage equilibrium in the ancestral populations. Evidence of disequilibrium is therefore attributed to population structure. On the other hand, snmf and DAPC are more relaxed in their assumptions and therefore more appropriate for analyses of inbred lineages and perhaps more complex patterns of population genetic structure (see Frichot et al. 2014; Jombart et al. 2010).

Under the hypothesis of the occurrence of three clusters, the rat population of the island of Ponza cannot be considered a distinct eradication unit. Ponza is the main island of the Archipelago from where ferries and private boats leave on daily basis to the other Pontine islands and the ports located on the Latium coast (i.e. Gaeta, Formia, Terracina and Anzio). This may suggest that one of the possible sources of black rats for Palmarola and Ventotene may be the harbour of Ponza, even if the relatively lower number of rats sampled on this island with respect to the other sampling sites might affect clustering computations. Therefore, we cannot rule out the presence of other source populations not included in this study and that movement of black rats may follow an inverse flow, from Ventotene and Palmarola to Ponza. However, considering the very low degree of migration across the Archipelago and the high selfrecruitment rates recorded within islands, it seems plausible to assume that in recent times exchange of individuals among Pontine islands has been negligible.

Mount Orlando is close to the Gaeta and Formia harbours from where boats regularly sail to Ponza and Ventotene islands. Black rats from this mainland sampling site are genetically distinct from those sampled in Palmarola and Ventotene, but they appear to be slightly admixed with Ponza, indicating that Mount Orlando and mainland locations nearby may be one of the main sources of rodents of the Pontine Archipelago. Again, this conclusion must be taken with caution given the low sampling size from Ponza.

\section{Population demographic history}

We described the demographic history of the Pontine black rat populations by using three different methods based on evidence of heterozygosity excess, shifts in allele frequencies and low ratios of allelic number to allelic size range, respectively. We obtained apparently incongruent results as previously reported by Iannucci et al. (2018) for the Tuscan Archipelago. Clear evidence of bottleneck events for all populations was in fact recovered by the M-ratio test only. Methods based on differences in the rate of reduction in the number of alleles versus gene diversity and those assessing shift in allele frequencies from an L-shaped distribution generally record recent evidence of bottlenecks, while the M-ratio test recovers historical reduction in population size (Garza and Williamson 2001; Marshall et al. 2009). The low M-ratio values recorded in this study therefore suggested that all black rat populations of the Pontine Archipelago went through a drastic reduction in population size, perhaps due to an old founder event (Abdelkrim et al. 2005; Iannucci et al. 2018).

Our results confirm previous hypothesis on the pattern of colonization of the Pontine Archipelago. Black rats were found in the western Mediterranean basin since Roman times (Ruffino et al. 2009). In Central Italy, in particular, records of $R$. rattus date back to the sixth century (Colangelo et al. 2015; De Grossi Mazorin 1987). Although several colonization and/or introduction events could have occurred over centuries, the Western Mediterranean black rat population appears to have originated following a single colonization event (Colangelo et al. 2015). A relatively high haplotype and nucleotide diversities and the presence of private haplotypes were, in fact, recorded especially for the island of Ponza, suggesting a recent in situ genetic diversification after colonization (Colangelo et al. 2015). Our results advocate this hypothesis, for we found a basically null gene flow between Ponza and Mount Orlando, and a low admixture between the two sampling sites, probably 
the result of a past colonization of Ponza from the mainland.

\section{Epidemiological investigations}

Relatively high relatedness values and evidence of past bottleneck may be explained by a number of factors. Among these, intra-specific competitions against new invaders may lead to the establishment of familiar groups of conspecifics (Granjon and Cheylan 1989; Fraser et al. 2015), while a massive use of rodenticides may result in human-driven bottlenecks of rat populations. Additionally, the spread of zoonotic diseases, carried by parasites as flies and ticks, can be another cause of a drastic reduction in population size, and it was probably one of the main factors affecting demography of the Pontine rat populations. In fact, our epidemiological assessment revealed the presence of $T$. gondii and some vector-borne pathogens, such as $L$. infantum, $B$. microti and B. afzelii, in the study area.

Leishmania infantum was detected with a lower prevalence with respect to southern Italy, where the parasite is hyperendemic, and Montecristo Island in the Tuscan Archipelago (Cringoli et al. 2002; Rossi et al. 2008; Zanet et al. 2014a). On the other hand, $T$. gondii infection was recorded with a high prevalence. The castor bean tick (Ixodes ricinus) is one of the most common tick in Italy and the main vector of Babesia sp. In this study, we recorded the co-infection of rats with two Babesia species, as already reported by Mehr-Scherrer (1999). The difference in prevalence found among the three Pontine islands (although not statistically significant) is evidence of a higher risk of infection by rats from Palmarola and Ventotene rather than those from Ponza. Based on the biology of $I$. ricinus, the less urbanized environment of Ventotene and Palmarola probably facilitates the persistence of the vector (Medlock et al. 2013).

\section{Conclusions}

In the last decades, several studies have described the detrimental impact of invasive black rats on Mediterranean endemisms and island ecosystems (e.g. Baccetti et al. 2009; Capizzi et al. 2010). For instance, in the Tuscan Archipelago, predation upon bird nestlings and eggs resulted in a decrease of several protected species. After pest control measures were adopted in this area, an increase in population size of autochthonous bird species was recorded (Baccetti et al. 2009; Sposimo et al. 2019). Similar results were recently documented for other insular ecosystems of the Mediterranean basin (e.g. Bourgeois et al. 2013; Canale et al. 2019). However, there are examples where rat eradication can fail, mainly as a consequence of a rapid re-colonization of the area from nearby sites and/or survival of rodenticide-resistant individuals (Howald et al. 2007).

In this study, which is the first of its kind on black rats in Italy, we did not record rats carrying mutations in $V K O R C l$ coding gene that would confer resistance to common anticoagulants. This result is particularly important as it suggests that less powerful secondgeneration anticoagulants (i.e. bromadiolone and difenacoum) can be used in the Pontine Archipelago as they appear to be efficient against rat populationsto be eradicated. This action should nevertheless be carefully evaluated since such compounds are highly bio-accumulative and thus potentially harmful to species of conservation concern, rodent predators and pets (Eason et al. 2002; Laakso et al. 2010; Vein et al. 2013). However, the importance of investigating the occurrence of resistance to anticoagulants is not limited to island ecosystems. Such an investigation should be performed beforehand in every eradication programs, both in urban and rural areas, in order to avoid the use of first-generation anticoagulants where resistant phenotypes are not recorded.

We also showed that in the Pontine Archipelago there are at least two distinct black rat eradication units located on the islands of Palmarola and Ventotene. Although it is likely that colonization of these islands occurred in historical times, our study suggests that the port of Ponza might have been a main source of the Ventotene and Palmarola rat populations. Eradication campaigns conducted on the islands of Palmarola and Ventotene should therefore be extended to Ponza and adopt long-term biosecurity measures in the harbours as well as regular monitoring of vessels connecting these islands.

Finally, the presence of $T$. gondii, B. microti, $L$. infantum and B. afzelii in black rats from the Pontine islands revealed the presence of vector-borne pathogens in commensal habitats of the Archipelago. Precautions and safety measures should therefore be adopted when coming in contact with rodents, 
especially during rat control campaigns. These results are therefore important not only for the preservation of local biodiversity but also for the protection of public health.

This study used for the first time a multidisciplinary approach where genetic and epidemiological methods are integrated to provide background information for devising and implementing eradication programs of black rats. We characterized the presence of resistant phenotypes, defined the boundaries of eradication units and evaluated the spread of zoonoses (with particular attention to those transmissible to humans). Such information is crucial to ensure successful eradication of rats, set up biosecurity measures to prevent future re-invasions and limit the risks to human and animal health in the study area. In a broader context, we advocate the importance of multidisciplinary studies in the implementation of eradication programs of rodents, and particularly for such initiatives conducted in island ecosystems.

Acknowledgements We are grateful to Flavia Fineschi, Alberto Masoni and Caterina Zuccagnoli for assistance with genetic analysis. We also thank Gaia De Luca, Marianna Di Santo and Ferdinando Corbi for providing black rat specimens. This research was funded by the European Commission LIFE project "Restoring the Pontine Archipelago ecosystem through the management of rats and other invasive alien speciesPonDerat LIFE14 NAT/IT/000544".

\section{Compliance with ethical standards}

Conflict of interest The authors declare that they have no conflicts of interest.

Informed consent Informed consent was obtained from all individual participants included in the study.

\section{References}

Abdelkrim J, Pascal M, Samadi S (2005) Island colonization and founder effects: the invasion of the Guadeloupe islands by ship rats (Rattus rattus). Mol Ecol 14:2923-2931

Abdelkrim J, Pascal M, Samadi S (2007) Establishing causes of eradication failure based on genetics: case study of ship rat eradication in Ste. Anne archipelago. Conserv Biol 21:719-730

Abdelkrim J, Pascal M, Samadi S (2009) Genetic structure and functioning of alien ship rat populations from a Corsican micro-insular complex. Biol Invasions 11:473-482

Baccetti N, Capizzi D, Corbi F et al (2009) Breeding shearwaters on Italian islands: population size, island selection and co-existence with their main alien predator, the black rat. Riv Ital Orn 78:83-100

Belkhir K, Borsa P, Chikhi L et al (1996-2004) GENETIX 4.05, logiciel sous Windows TM pour la génétique des populations. Montpellier (France): Laboratoire Génome, Populations, Interactions, CNRS UMR 5171. Université de Montpellier II

Beninati T, Piccolo G, Rizzoli A et al (2006) Anaplasmataceae in wild rodents and roe deer from Trento Province (northern Italy). Eur J Clin Microbiol Infect Dis 25:677-678

Bourgeois K, Ouni R, Pascal M et al (2013) Dramatic increase in the Zembretta Yelkouan shearwater breeding population following ship rat eradication spurs interest in managing a 1500-year old invasion. Biol Invasions 15:475-482

Boyle CM (1960) Case of apparent resistance of Rattus norvegicus Berkenhout to anticoagulant poisons. Nature 188:517-525

Canale DE, Di Dio V, Massa B et al (2019) First successful eradication of invasive Norway rats Rattus norvegicus from a small Mediterranean island (Isola delle Femmine, Italy). Folia Zool 68:21-26

Capizzi D, Baccetti N, Sposimo P (2010) Prioritizing rat eradication on islands by cost and effectiveness to protect nesting seabirds. Biol Conserv 143:1716-1727

Capizzi D, Bertolino S, Mortelliti A (2014) Rating the rat: global patterns and research priorities in impacts and management of rodent pests. Mammal Rev 44:148-162

Capizzi D, Baccetti N, Sposimo P (2016) Fifteen years of rat eradication on Italian islands. In: Angelici FM (ed) Problematic wildlife. Springer International Publishing, Cham, pp 205-227

Capizzi D, Monaco A, Genovesi P et al (2018) Impact of alien mammals on public health. In: Mazza G, Tricarico E (eds) Invasive species and human health. CAB International, Wallingford, pp 130-150

Celesti-Grapow L, Abbate G, Baccetti N et al (2017) Control of invasive species for the conservation of biodiversity in Mediterranean islands. The LIFE PonDerat project in the Pontine Archipelago, Italy. Plant Biosyst 151:795-799

Chapuis M-P, Estoup A (2006) Microsatellite null alleles and estimation of population differentiation. Mol Biol Evol 24:621-631

Colangelo P, Abiadh A, Aloise G et al (2015) Mitochondrial phylogeography of the black rat supports a single invasion of the western Mediterranean basin. Biol Invasions 17:1859-1868

Cornuet JM, Luikart G (1996) Description and power analysis of two tests for detecting recent population bottlenecks from allele frequency data. Genetics 144:2001-2014

Courchamp F, Chapuis JL, Pascal M (2003) Mammal invaders on islands: impact, control and control impact. Biol Rev 78:347-383

Cringoli G, Rinaldi L, Capuano F et al (2002) Serological survey of Neospora caninum and Leishmania infantum co-infection in dogs. Vet Parasitol 106:307-313

Daszak P, Cunningham AA, Hyatt AD (2000) Emerging infectious diseases of wildlife-threats to biodiversity and human health. Science 287:443-449 
Davis S, Calvet E (2005) Fluctuating rodent populations and risk to humans from rodent-borne zoonoses. Vector Borne Zoonotic Dis 5:305-314

De Grossi Mazorin J (1987) La fauna. In: Ghini G (ed) Archeologia Laziale VIII. CNR, Roma, pp 234-235

Doherty TS, Glen AS, Nimmo DG et al (2016) Invasive predators and global biodiversity loss. Proc Natl Acad Sci 113:11261-11265

Dubey J (1998) Advances in the life cycle of Toxoplasma gondii. Int J Parasitol 28:1019-1024

Eason CT, Murphy EC, Wright GR et al (2002) Assessment of risks of brodifacoum to non-target birds and mammals in New Zealand. Ecotoxicology 11:35-48

Evanno G, Regnaut S, Goudet J (2005) Detecting the number of clusters of individuals using the software STRUCTURE: a simulation study. Mol Ecol 14:2611-2620

Excoffier L, Lischer HE (2010) Arlequin suite ver 3.5: a new series of programs to perform population genetics analyses under Linux and Windows. Mol Ecol Resour 10:564-567

Frankham R, Briscoe DA, Ballou JD (2010) Introduction to conservation genetics, 2nd edn. Cambridge University Press, Cambridge

Fraser CI, Banks S, Waters S (2015) Priority effects can lead to underestimation of dispersal and invasion potential. Biol Invas 17(1):1-8

Frichot E, François O (2015) LEA: an R package for landscape and ecological association studies. Methods Ecol Evol 6:925-929

Frichot E, Mathieu F, Trouillon T et al (2014) Fast and efficient estimation of individual ancestry coefficients. Genetics 196:973-983

Garza J, Williamson E (2001) Detection of reduction in population size using data from microsatellite loci. Mol Ecol 10:305-318

Goudet J (1995) FSTAT (version 1.2): a computer program to calculate F-statistics. J Hered 86:485-486

Goulois J, Chapuzet A, Lambert V et al (2016) Evidence of a target resistance to antivitamin $\mathrm{K}$ rodenticides in the roof rat Rattus rattus: identification and characterisation of a novel Y25F mutation in the Vkorcl gene. Pest Manag Sci 72:544-550

Goulois J, Hascoët C, Dorani K et al (2017) Study of the efficiency of anticoagulant rodenticides to control Mus musculus domesticus introgressed with Mus spretus Vkorcl. Pest Manag Sci 73:325-331

Graham MF, Veitch CR (2002) Changes in bird numbers on Tiritiri Matangi Island, New Zealand, over the period of rat eradication. In: Clout MN, Veitch CR (eds) Turning the tide: the eradication of invasive species. IUCN SSC Invasive Species Specialist Group, Gland, pp 120-123

Grandemange A, Kohn MH, Lasseur R et al (2009) Consequences of the Y139F Vkorcl mutation on resistance to AVKs: in vivo investigation in a 7 th generation of congenic Y139F strain of rats. Pharmacogen Genomics 19:742-750

Granjon L, Cheylan G (1989) Le sort de rats noirs (Rattus rattus) introduits sur une île, révélé par radiotracking. C R Acad Sci Serie III 309:571-575

Hinten G, Rossetto M, Baverstock P (2007) New microsatellite markers for the bush rat, Rattus fuscipes greyii: characterization and cross-species amplification. Mol Ecol Notes $7: 1254-1257$
Howald G, Donlan CJ, Galvan JP et al (2007) Invasive rodent eradication on islands. Conserv Biol 21:1258-1268

Iacucci A, Colangelo P, Gamberi V et al (2018) VKORC1 mutation in European populations of Rattus norvegicus with first data for Italy and the report of a new amino acid substitution. Hystrix 29:95-99

Iannucci A, Natali C, Ciofi C et al (2018) Population genetic analysis of invasive black rats: defining eradication units in the Tuscan Archipelago National Park. Hystrix 29:67-73

Iannucci A, Natali C, Capizzi D et al (2019) First record of VKORC1 sequence mutation associated with resistance to anticoagulant rodenticides in Italian strains of Mus musculus. Hystrix. https://doi.org/10.4404/hystrix-00193-2019

Jacob HJ, Brown DM, Bunker RK et al (1995) A genetic linkage map of the laboratory rat, Rattus norvegicus. Nat Genet 9:63-69

Jombart T, Collins C (2015) A tutorial for discriminant analysis of principal components (DAPC) using adegenet 2.0.0. Imperial College London, London

Jombart T, Devillard S, Balloux F (2010) Discriminant analysis of principal components: a new method for the analysis of genetically structured populations. BMC Genet 11:94

Kearse M, Moir R, Wilson A et al (2012) Geneious Basic: an integrated and extendable desktop software platform for the organization and analysis of sequence data. Bioinformatics 28:1647-1649

Keitt B, Campbell K, Saunders A et al (2011) The Global Islands Invasive Vertebrate Eradication Database: a tool to improve and facilitate restoration of island ecosystems. In: Veitch CR, Clout MN, Towns DR (eds) Island invasives: eradication and management. IUCN, Gland, pp 74-77

Kerbiriou C, Pascal M, Le Viol I et al (2004) Consequence sur l'avifaune terrestre de l'Ile de Trielen (reserve naturelle d'Iroise; Bretagne) de l'eradication du surmulot (Rattus norvegicus). Rev Ecol Terre Vie 59:319-329

Kumar S, Stecher G, Li M et al (2018) MEGA X: molecular evolutionary genetics analysis across computing platforms. Mol Biol Evol 35:1547-1549

Laakso S, Suomalainen K, Koivisto S (2010) Literature review on residues of anticoagulant rodenticides in non-target animals. Nordic Council of Ministers, TemaNord

Lowe S, Browne M, Boudjelas S et al (2000) 100 of the world's worst invasive alien species: a selection from the global invasive species database. Invasive Species Specialist Group, Auckland

Luikart G, Allendorf F, Cornuet J et al (1998) Distortion of allele frequency distributions provides a test for recent population bottlenecks. J Hered 89:238-247

Lynch M, Ritland K (1999) Estimation of pairwise relatedness with molecular markers. Genetics 152:1753-1766

Marshall JC, Kingsbury BA, Minchella DJ (2009) Microsatellite variation, population structure, and bottlenecks in the threatened copperbelly water snake. Conserv Genet 10:465-476

Medlock JM, Hansford KM, Bormane A et al (2013) Driving forces for changes in geographical distribution of Ixodes ricinus ticks in Europe. Parasites Vectors 6:1

Meerburg BG, Singleton GR, Kijlstra A (2009) Rodent-borne diseases and their risks for public health. Crit Rev Microbiol 35:221-270 
Mehr-Scherrer L (1999) Babesia-Infektionen nun auch in der Schweiz? Bulletin of the Swiss Federal Office of Public Health 978-979

Pascal M, Siorat F, Lorvelec O et al (2005) A pleasing consequence of Norway rat eradication: two shrew species recover. Divers Distrib 11:193-198

Peakall R, Smouse PE (2006) GENALEX 6: genetic analysis in Excel. Population genetic software for teaching and research. Mol Ecol Notes 6:288-295

Pelz H-J, Prescott CV (2015) Resistance to anticoagulant rodenticides. In: Buckle AR, Smith RH (eds) Rodent pests and their control, 2nd edn. CAB International, Wallingford, pp 101-122

Pelz H-J, Rost S, Hünerberg M et al (2005) The genetic basis of resistance to anticoagulants in rodents. Genetics 170:1839-1847

Piry S, Luikart G, Cornuet J (1999) BOTTLENECK: a computer program for detecting recent reductions in the effective population size using allele frequency data. J Hered 90:502-503

Pritchard JK, Stephens M, Donnelly P (2000) Inference of population structure using multilocus genotype data. Genetics 155:945-959

Ragionieri L, Cutuli G, Sposimo P et al (2013) Establishing the eradication unit of Molara Island: a case of study from Sardinia, Italy. Biol Invasions 15:2731-2742

Ramasamy RK, Ramasamy S, Bindroo BB et al (2014) STRUCTURE PLOT: a program for drawing elegant STRUCTURE bar plots in user friendly interface. SpringerPlus 3:431

Rice WR (1989) Analyzing tables of statistical tests. Evolution 43:223-225

Rijpkema S, Molkenboer M, Schouls LM et al (1995) Simultaneous detection and genotyping of three genomic groups of Borrelia burgdorferi sensu lato in Dutch Ixodes ricinus ticks by characterization of the amplified intergenic spacer region between 5S and 23S rRNA genes. J Clin Microbiol 33:3091-3095

Robertson BC, Gemmell NJ (2004) Defining eradication units to control invasive pests. J Appl Ecol 41:1042-1048

Rossi E, Bongiorno G, Ciolli E et al (2008) Seasonal phenology, host-blood feeding preferences and natural Leishmania infection of Phlebotomus perniciosus (Diptera, Psychodidae) in a high-endemic focus of canine leishmaniasis in Rome province, Italy. Acta Trop 105:158-165

Rosso F, Tagliapietra V, Baráková I et al (2017) Prevalence and genetic variability of Anaplasma phagocytophilum in wild rodents from the Italian Alps. Parasites Vectors 10:293

Rost S, Fregin A, Ivaskevicius V et al (2004) Mutations in VKORC1 cause warfarin resistance and multiple coagulation factor deficiency type 2. Nature 427:537-541

Rost S, Pelz H-J, Menzel S et al (2009) Novel mutations in the VKORC1 gene of wild rats and mice-a response to 50 years of selection pressure by warfarin? BMC Genet 10:4

Rousset F (2008) genepop'007: a complete re-implementation of the genepop software for Windows and Linux. Mol Ecol Resour 8:103-106
Ruffino L, Bourgeois K, Vidal E et al (2009) Invasive rats and seabirds after 2,000 years of an unwanted coexistence on Mediterranean islands. Biol Invasions 11:1631-1651

Russell JC, Towns DR, Clout M (2008) Review of rat invasion biology: Implications for island biosecurity. Science for Conservation 286. New Zealand Department of Conservation, Wellington

Sambrook J, Russell DW (2001) Molecular cloning: a laboratory manual. Cold Spring Harbor Laboratory, Cold Spring Harbor

Savidge JA, Hopken MW, Witmer GW et al (2012) Genetic evaluation of an attempted Rattus rattus eradication on Congo Cay, US Virgin Islands, identifies importance of eradication units. Biol Invasions 14:2343-2354

Sposimo P, Capizzi D, Cencetti T et al (2019) Rat and lagomorph eradication on two large islands of central Mediterranean: differences in island morphology and consequences on methods, problems and targets. In: Veitch CR, Clout MN, Martin AR, Russell JC, West CJ (eds) Island invasives: scaling up to meet the challenge. Occasional Paper SSC no. 62. IUCN, Gland, pp 231-235

Stenseth NC, Leirs H, Skonhoft A et al (2003) Mice, rats, and people: the bio-economics of agricultural rodent pests. Front Ecol Environ 1:367-375

Tanaka KD, Kawai YK, Ikenaka Y et al (2012) The genetic mechanisms of warfarin resistance in Rattus rattus found in the wild in Japan. Pestic Biochem Physiol 103:144-151

Towns DR, Daugherty CH, Cree A (2001) Raising the prospects for a forgotten fauna: a review of 10 years of conservation effort for New Zealand reptiles. Biol Conserv 99:3-16

Towns DR, Atkinson IA, Daugherty CH (2006) Have the harmful effects of introduced rats on islands been exaggerated? Biol Invasions 8:863-891

Trisciuoglio A, Zanet S, Marello G et al (2015) The use of loopmediated isothermal amplification improves Toxoplasma gondii detection in wildlife. J Vet Diagn Invest 27:754-757

Van den Brink NW, Elliott JE, Shore RF et al (2018) Anticoagulant rodenticides and wildlife. Springer International Publishing, NY

Van Oosterhout C, Hutchinson WF, Wills DP et al (2004) MICRO-CHECKER: software for identifying and correcting genotyping errors in microsatellite data. Mol Ecol Notes 4:535-538

Vein J, Vey D, Fourel I et al (2013) Bioaccumulation of chlorophacinone in strains of rats resistant to anticoagulants. Pest Manag Sci 69:397-402

Vié J-C, Hilton-Taylor C, Stuart SN (2009) Wildlife in a changing world: an analysis of the 2008 IUCN Red List of threatened species. IUCN, Gland

Vilà M, Basnou C, Pyšek P et al (2010) How well do we understand the impacts of alien species on ecosystem services? A pan-European, cross-taxa assessment. Front Ecol Environ 8:135-144

Webster J, Ellis W, Macdonald D (1995) Prevalence of Leptospira spp. in wild brown rats (Rattus norvegicus) on UK farms. Epidemiol Infect 114:195-201

Willows-Munro S, Dowler RC, Jarcho MR et al (2016) Cryptic diversity in Black rats Rattus rattus of the Galápagos Islands, Ecuador. Ecol Evolut 6:3721-3733 
Wilson GA, Rannala B (2003) Bayesian inference of recent migration rates using multilocus genotypes. Genetics 163:1177-1191

Zanet S, Sposimo P, Trisciuoglio A et al (2014a) Epidemiology of Leishmania infantum, Toxoplasma gondii, and Neospora caninum in Rattus rattus in absence of domestic reservoir and definitive hosts. Vet Parasitol 199:247-249

Zanet S, Trisciuoglio A, Bottero E et al (2014b) Piroplasmosis in wildlife: Babesia and Theileria affecting free-ranging ungulates and carnivores in the Italian Alps. Parasites Vectors 7:70

Publisher's Note Springer Nature remains neutral with regard to jurisdictional claims in published maps and institutional affiliations. 